\title{
Study of Models for Predicting the Mean Hourly Global Radiation from Daily Summations
}

\author{
M. Jamil Ahmad and G.N. Tiwari* \\ Center for Energy Studies, Indian Institute of Technology, Hauz Khas, New Delhi 110016, India
}

\begin{abstract}
It is mandatory to predict the hourly solar radiation received during the average day of each month for different solar energy applications, particularly in design methods, Scientists have developed methods to achieve this using different input parameters. The objective of this study is to compare statistically existing models for estimating the mean hourly global radiation incident on a horizontal surface from mean daily global radiation and to recommend one that best fits measured data from five Indian locations chosen namely, Bangalore, Jodhpur, Mumbai, New Delhi and Srinagar. From our results it is observed that Collares-Pereira and Rabl model as modified by Gueymard (CPRG) yields the best performance for estimating mean hourly global radiation incident on a horizontal surface for Indian regions. In addition to CPRG model, Collares-Pereira and Rabl (CPR) and Whillier /Liu and Jordan (WLJ) models yield better performance than Newell, Baig and Garg models. Moreover each model gives an average amount of under-estimation in the calculated value.
\end{abstract}

Keywords: Hourly global radiation, Indian region, statistical comparison.

\section{INTRODUCTION}

Accurate determination of the hourly solar radiation received during the average day of each month is a prerequisite in different solar energy applications, particularly in design methods. As soon as the early 1950s, Whillier [1,2] introduced the 'utilisability' method to predict analytically the performance of active solar collectors (see also [3]). This method used a simple formulation to estimate the mean hourly radiation during each hour of an average day of the month, based on the ratio of the hourly to daily irradiations received by a horizontal surface outside of the atmosphere. This methodology has been perfected.

The emphasis is placed here on the prediction of the monthly-average hourly global radiation over a 'long-term' period of around eleven years as opposed to individual hourly periods for a specific day and a specific year. In other words, the long-term calculations involved here provide the mean hourly distribution of global radiation over the average day of each average month. The daily integration approach introduced by Whillier involved the hourly/daily radiation ratio just mentioned and received much attention in the literature. Some early reports were of qualitative nature (e.g. [4-6]). Liu and Jordan generalized Whillier's finding by adding a few datapoints from a Canadian site. Another key contribution was the model introduced by Collares-Pereira and Rabl [7]; hereafter, CPR, who modified the original Whillier formulation. CPR realized that the atmospheric attenuation of direct and global radiation had a dependency upon hour angle. They used a dataset combining two years of individual hourly data from four U.S. stations and the original data of

*Address correspondence to these authors at the Center for Energy Studies, Indian Institute of Technology, Hauz Khas, New Delhi 110016, India; E-mail: gntiwari@ces.iitd.ac.in
[4], and proposed a correction to the original equations by Whillier or Liu and Jordan which assumed no atmospheric effect. CPR also pointed out that the interest of such a method was that it could predict hourly radiation a (which is a rarely available quantity at any site) from straightforward information: hour angle and mean daily irradiation, $H$.

Gueymard [8] proposed a slight correction to the CPR model (hereafter, CPRG) to make it internally consistent. He also showed that morning/afternoon asymmetries could limit the accuracy of the predicted mean hourly radiation. This asymmetry problem received more attention later [9-13]. Following CPR, it is assessed here that only daily radiation values are available at any site; there is no way to predict asymmetric irradiations during the day from just daily global information.

It was demonstrated [14] that the hourly/daily ratio is significantly affected by latitude and solar elevation. This finding prompts a closer examination of the latitudinal, or more generally, climatic influences on the daily integration method. This constitutes the main objective of the present study.

In the mathematical approach, the diurnal variation of the hourly/daily radiation ratio is simulated with different types of mathematical formula of time. It is still not clear which mathematical representation is best to describe the physical processes involved. Cosine distributions have been proposed [15-17], as well as a quadratic [17], various forms of exponentials or Gaussian distributions [18-22]. Despite their merit, the accuracy of these methods is not established. In particular, it remains to be seen which, of the daily integration or the mathematical approach, is better when applied to a site where daily radiation can only be indirectly obtained, from mean monthly sunshine or cloudiness information for 
instance. Elements to answer this question will be proposed here.

In this paper, the various models to determine the hourly solar radiation for different Indian climatic conditions have been studied to predict the best model on the basis of RMSE and MBE. It is observed that CPRG model is most suitable for clear sky condition of Indian climatic conditions.

\section{EXPERIMENTAL DATA}

Long term monthly-mean hourly global radiation data for a measuring site are obtained from hourly global radiation by averaging individual hourly values for each month over a period of one to eleven years. The long term monthly-mean daily global irradiation is obtained as the sum of each individual hourly irradiation for that day. The solar radiation data have been collected for the period of 1991-2001 from India Meteorology Department (IMD) Pune, India. Using this source of data, a dataset of global radiation for a total of five sites has been assembled. This dataset encompasses a large diversity of climatic conditions, including desertic (hot and dry), coastal (warm and humid), moderate, cold with cloudy and composite. This diversity is associated with a very large altitude (elevation) span, which ranges from $11 \mathrm{~m}$ to $1586 \mathrm{~m}$ above mean sea level. The typical data for New Delhi climate has been given in Table $\mathbf{1}$.

The present results are based on a large number of different instrument types, calibration methods, and climates, so that the overall error should remain small. Most other errors are random, and they tend to decrease rapidly as the averaging period increases. Therefore, they should be negligible here.

These data have been obtained using a thermoelectric pyranometer. The pyranometer used are supposed to be calibrated once a year with reference to the World Radiometric Reference (WRR). Critical information such as calibration history, instrument changes, data quality control process, and shading due to obstructions in the horizon, is simply not available for these stations. Therefore it is to be expected that some data sites have larger uncertainties, with possibly more

incorrect or missing data than others. But this situation is also confronted by any investigator using this kind of radiation data directly to design solar energy systems.

\section{METHODOLOGY}

In what follows, all calculations are made on an average hourly basis. The solar geometry need be determined for only an average day of each month. The average days of the month are taken from [23].

The day length (in hours) is simply obtained as:

$S_{o}=k \omega_{o}$

where $k=24 / \pi, \omega_{o}$ is the sunrise hour angle (in radians) obtained from

$\cos \omega_{o}=-\tan \phi \tan \delta$

where $\phi$ is the site's latitude, $\delta$ is solar declination obtained from

$\delta=23.45 \sin \left[\frac{360}{365}(284+n)\right]$

where $n$ is the day of the year i.e. 1 for Jan 1 .

\section{EXISTING MODELS}

Whillier/Liu and Jordan model (WLJ): In this model, global radiation is considered to follow the same hourly distribution as if there were no atmosphere. For an hourly period evaluated at the middle of the hourly interval, according to the present procedure, the extraterrestrial hourly/daily ratio can be obtained (see derivation in $[2,4,6]$ ) simply as:

Table 1. Measured Average Hourly Global Solar Radiations for Clear Sky Weather Condition (W/m²) for New Delhi

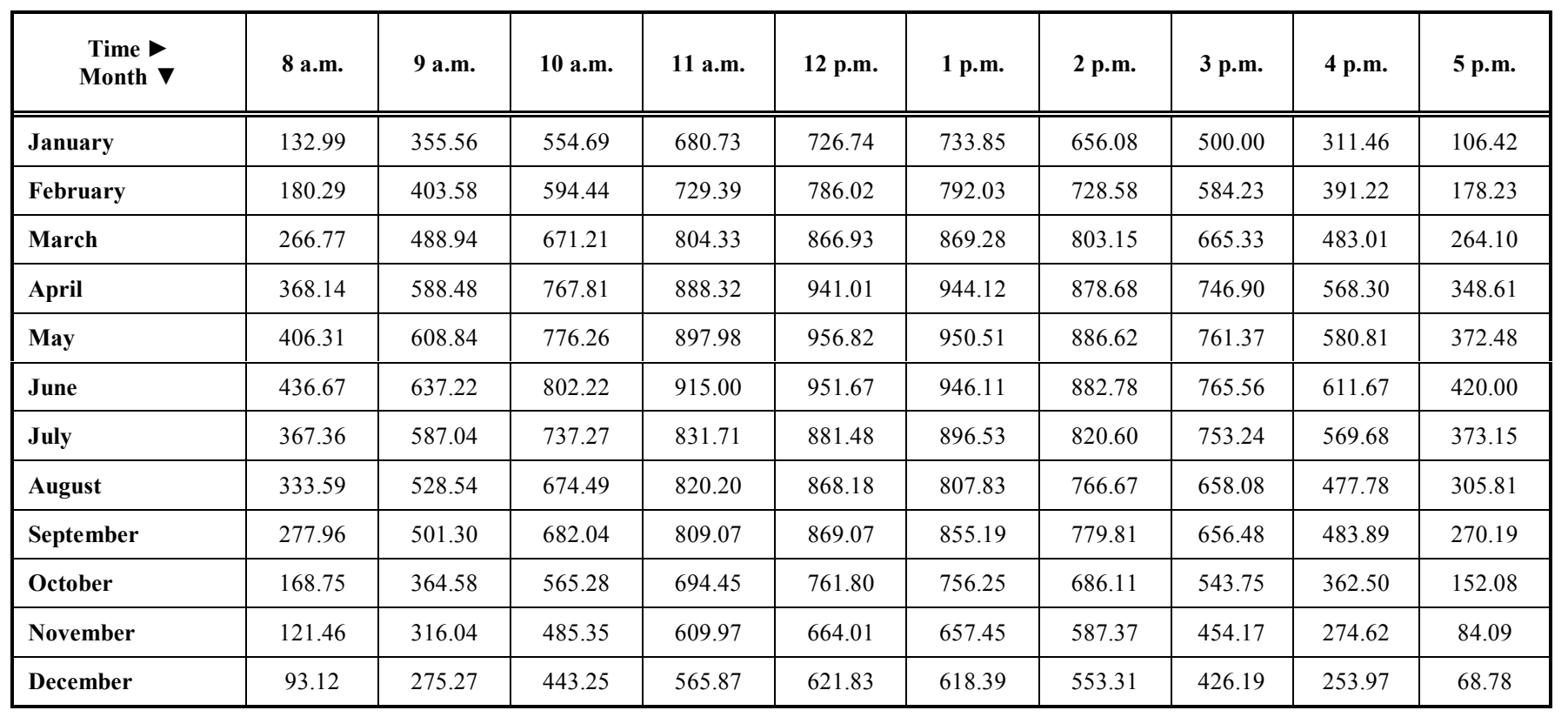


$r_{0}=\left(\cos \omega-\cos \omega_{o}\right) / k A\left(\omega_{o}\right)$

where $A\left(\omega_{o}\right)=\sin \omega_{o}-\omega_{o} \cos \omega_{o}$

Table 2. Recommended Average Days for Months and Values of $\mathbf{n}$ by Months

\begin{tabular}{|l|c|c|c|c|}
\hline \multirow{2}{*}{ Months } & \multirow{2}{*}{$\begin{array}{c}\text { n for } \boldsymbol{i t h} \text { Day } \\
\text { of Month }\end{array}$} & \multicolumn{3}{c|}{ For Average Day of Month } \\
\cline { 3 - 5 } & & Date & n & $\boldsymbol{\delta}$ \\
\hline \hline January & $i$ & 17 & 17 & -20.9 \\
\hline February & $31+i$ & 16 & 47 & -13.0 \\
\hline March & $59+i$ & 16 & 75 & -2.4 \\
\hline April & $90+i$ & 15 & 105 & 9.4 \\
\hline May & $120+i$ & 15 & 135 & 18.8 \\
\hline June & $151+i$ & 11 & 162 & 23.1 \\
\hline July & $181+i$ & 17 & 198 & 21.2 \\
\hline August & $212+i$ & 16 & 228 & 13.5 \\
\hline September & $243+i$ & 15 & 258 & 2.2 \\
\hline October & $273+i$ & 15 & 288 & -9.6 \\
\hline November & $304+i$ & 14 & 318 & -18.9 \\
\hline December & $334+i$ & 10 & 344 & -23.0 \\
\hline
\end{tabular}

Table 3. Latitude and Altitude of the Locations Used in this Study

\begin{tabular}{|c|c|c|}
\hline Location & Latitude & Altitude (m) \\
\hline \hline Bangalore & $12^{\circ} 58^{\prime} \mathrm{N}$ & 921 \\
\hline Jodhpur & $26^{\circ} 18^{\prime} \mathrm{N}$ & 224 \\
\hline Mumbai & $18^{\circ} 54^{\prime} \mathrm{N}$ & 11 \\
\hline New Delhi & $28^{\circ} 35^{\prime} \mathrm{N}$ & 216 \\
\hline Srinagar & $34^{\circ} 05^{\prime} \mathrm{N}$ & 1586 \\
\hline
\end{tabular}

Collares-Pereira and Rabl model (CPR). The CPR model corrects WLJ's $r$ for the atmospheric effect as follows:

$r_{C P R}=(a+b \cos \omega) r_{o}$

where $a$ and $b$ are linear functions of

$\sin \left(\omega_{o}-\pi / 3\right)[7]$.

and are given by

$a=0.4090+0.5016 \sin \left(\omega_{o}-1.047\right)$

$b=0.6609-0.4767 \sin \left(\omega_{o}-1.047\right)$

Collares-Pereira and Rabl model as modified by Gueymard $(C P R G)$. The CPRG model [8] consists in a slight modification of to ensure consistency through renormalization
$r_{C P R G}=(a+b \cos \omega) r_{o} / f$

where $f=a+0.5 b\left(\omega_{o}-\sin w_{o} \cos \omega_{o}\right) / A\left(\omega_{o}\right)$

Newell model $(N)$. There are, in fact, two slightly differing models from Newell [17]. For simplicity, only the parabolic function of time will be tested here as an example of Newell's 'simple modeling approach'

$r_{N}=\left(1.5 / S_{o}\right)\left[1-4(t-12)^{2} / S_{o}^{2}\right]$

where $S_{o}$ is evaluated from (1)

Jain model $(J)$. Based on the normal distribution equation, Jain [9] proposed

$r_{J}=\frac{1}{\sigma_{J} \sqrt{2 \pi}} \exp \left[-\frac{(t-12)^{2}}{2 \sigma_{J}^{2}}\right]$

where $\sigma_{J}=0.461+0.192 S_{o}$

Baig et al. model $(B)$. Jain's exponential model is corrected in Baig model with a cosine function for better accuracy around sunrise and sunset [20]

$$
r_{B}=\frac{1}{2 \sigma_{B} \sqrt{2 \pi}} \exp \left\{\left[-\frac{(t-12)^{2}}{2 \sigma_{B}^{2}}\right]+\cos \left[\pi(t-12) /\left(S_{o}-1\right)\right]\right\}
$$

where $\sigma_{B}=0.26+0.21 S_{o}$

Garg and Garg Model (G). Garg and Garg [25] checked the adequacy of WLJ model for various Indian stations and showed that the model is not suitable for predicting the hourly solar radiation received during the average day of each month. Therefore they proposed the following new model.

$r_{G}=r_{o}-0.008 \sin 3(\omega-0.65)$

Measured values of radiation ratio are computed as

$r_{\text {meas }}=\frac{\bar{I}}{\bar{H}}$

where

$r_{\text {meas }}$ is the measured radiation ratio,

$\bar{I}$ is the measured monthly mean hourly global radiation and

$\bar{H}$ is the measured monthly mean daily global radiation.

\section{Methods of Comparison}

In this study two statistical test, root mean square error (RMSE) and mean bias error (MBE), are used to evaluate the accuracy of the models described above.

\section{Root Mean Square Error}

The root mean square error is defined as 
Table 4. Percentage Root Mean Square Error (RMSE) between Predicted Results and Measured Monthly-Mean Hourly Irradiation for Location Bangalore

\begin{tabular}{|c|c|c|c|c|c|c|c|c|}
\hline & & WLJ & CPR & CPRG & Newell & Jain & Baig & Garg \\
\hline \multirow{2}{*}{ January } & RMSE & 16.8 & 15.8 & 15.7 & 18.4 & 16.7 & 16.3 & 17.1 \\
\hline & MBE & -2.4 & -2.6 & -1.77 & -2.67 & -6.08 & -3.8 & -3.4 \\
\hline \multirow{2}{*}{ February } & RMSE & 18.2 & 17.8 & 17.8 & 19.4 & 18.8 & 18.3 & 18.2 \\
\hline & MBE & -2.9 & -3.1 & -2.2 & -3.3 & -6.6 & -3.9 & -4 \\
\hline \multirow{2}{*}{ March } & RMSE & 18.2 & 17 & 16.9 & 19.8 & 17.8 & 17.2 & 18.2 \\
\hline & MBE & -3.7 & -3.6 & -2.8 & -4.3 & -7.2 & -4.3 & -4.8 \\
\hline \multirow{2}{*}{ April } & RMSE & 16.7 & 14.1 & 13.8 & 19.3 & 15.3 & 14.1 & 16.1 \\
\hline & MBE & -4.7 & -4.4 & -3.6 & -5.4 & -7.9 & -4.7 & -5.8 \\
\hline \multirow{2}{*}{ May } & RMSE & 13.9 & 11.9 & 11.6 & 16.6 & 14.1 & 12 & 13.8 \\
\hline & MBE & -5.6 & -5 & -4.3 & -6.4 & -8.5 & -5.2 & -6.6 \\
\hline \multirow{2}{*}{ June } & RMSE & 15.4 & 14.1 & 13.9 & 17.5 & 16.3 & 14.3 & 15.8 \\
\hline & MBE & -6 & -5.3 & -4.7 & -6.9 & -8.9 & -5.5 & -7.1 \\
\hline \multirow{2}{*}{ July } & RMSE & 13.7 & 11.4 & 11.1 & 16.4 & 13.5 & 11.5 & 13.3 \\
\hline & MBE & -5.8 & -5.2 & -4.5 & -6.7 & -8.7 & -5.3 & -6.9 \\
\hline \multirow{2}{*}{ August } & RMSE & 12.5 & 9.5 & 9.2 & 15.4 & 11.6 & 9.6 & 11.3 \\
\hline & MBE & -5.1 & -4.6 & -3.9 & -5.8 & -8.2 & -4.9 & -6.2 \\
\hline \multirow{2}{*}{ September } & RMSE & 15.1 & 11.7 & 11.5 & 17.9 & 12.6 & 11.7 & 13.2 \\
\hline & MBE & -4.1 & -3.9 & -3.1 & -4.7 & -7.5 & -4.4 & -5.2 \\
\hline \multirow{2}{*}{ October } & RMSE & 13.4 & 10.8 & 10.6 & 16 & 12.1 & 11.1 & 12.4 \\
\hline & MBE & -3.2 & -3.3 & -2.4 & -3.6 & -6.8 & -4 & -4.3 \\
\hline \multirow{2}{*}{ November } & RMSE & 14.2 & 13.1 & 13 & 16 & 14.6 & 13.8 & 14.4 \\
\hline & MBE & -2.5 & -2.7 & -1.8 & -2.8 & -6.2 & -3.8 & -3.5 \\
\hline \multirow{2}{*}{ December } & RMSE & 19 & 17.6 & 17.5 & 20.6 & 18.3 & 18 & 19 \\
\hline & MBE & -2.2 & -2.5 & -1.6 & -2.5 & -5.9 & -3.8 & -3.3 \\
\hline
\end{tabular}

$R M S E=\left\{\left[\sum\left(r_{i, \text { calc }}-r_{i, \text { meas }}\right)^{2}\right] / n\right\}^{1 / 2}$

where $r_{i, \text { calc }}$ is the ith calculated value, $r_{i, \text { meas }}$ is the ith measured value, and $n$ is the total number of observations. The RMSE is always positive, a zero value is ideal. This test provides information on the short-term performance of the models by allowing a term by term comparison of the actual deviation between the calculated value and the measured value. However a few large errors in the sum can produce a significant increase in RMSE.

\section{Mean Bias Error}

The mean bias error is defined as

$$
M B E=\left[\sum\left(r_{i, \text { calc }}-r_{i, \text { meas }}\right)\right] / n
$$

This test provides information on the long-term performance. A low MBE is desired. Ideally a zero value of MBE should be obtained. A positive value gives the average amount of over-estimation in the calculated value and vice versa. One drawback of this test is that over-estimation of an individual observation will cancel under-estimation in a separate observation.

\section{RESULTS}

For known values of latitude (Table 3), the values of ' $a$ ', ' $b$ ' and ' $f$ ' have been computed from Equations 5(a), 5(b) and 7 respectively. After evaluating ' $a$ ', ' $b$ ' and ' $f$ ', the radiation ratio proposed by various models [Equations 4 to 11] can be evaluated. Further, the measured values of the average monthly mean hourly global radiation can be determined from Equation (12) for known values of monthly daily global radiation.

For typical data of New Delhi (Table 1), the variation of average monthly mean hourly global radiation has been shown in Fig. (1) for the month of June. The observed average monthly mean hourly global radiation for the month of June has also been shown in Fig. (1). It is noted that there CPRG model predicts the best result in comparison to other models.

Equations 13 and 14 have been computed for all months of five stations and the results for clear sky conditions are given in Tables 4-8. 

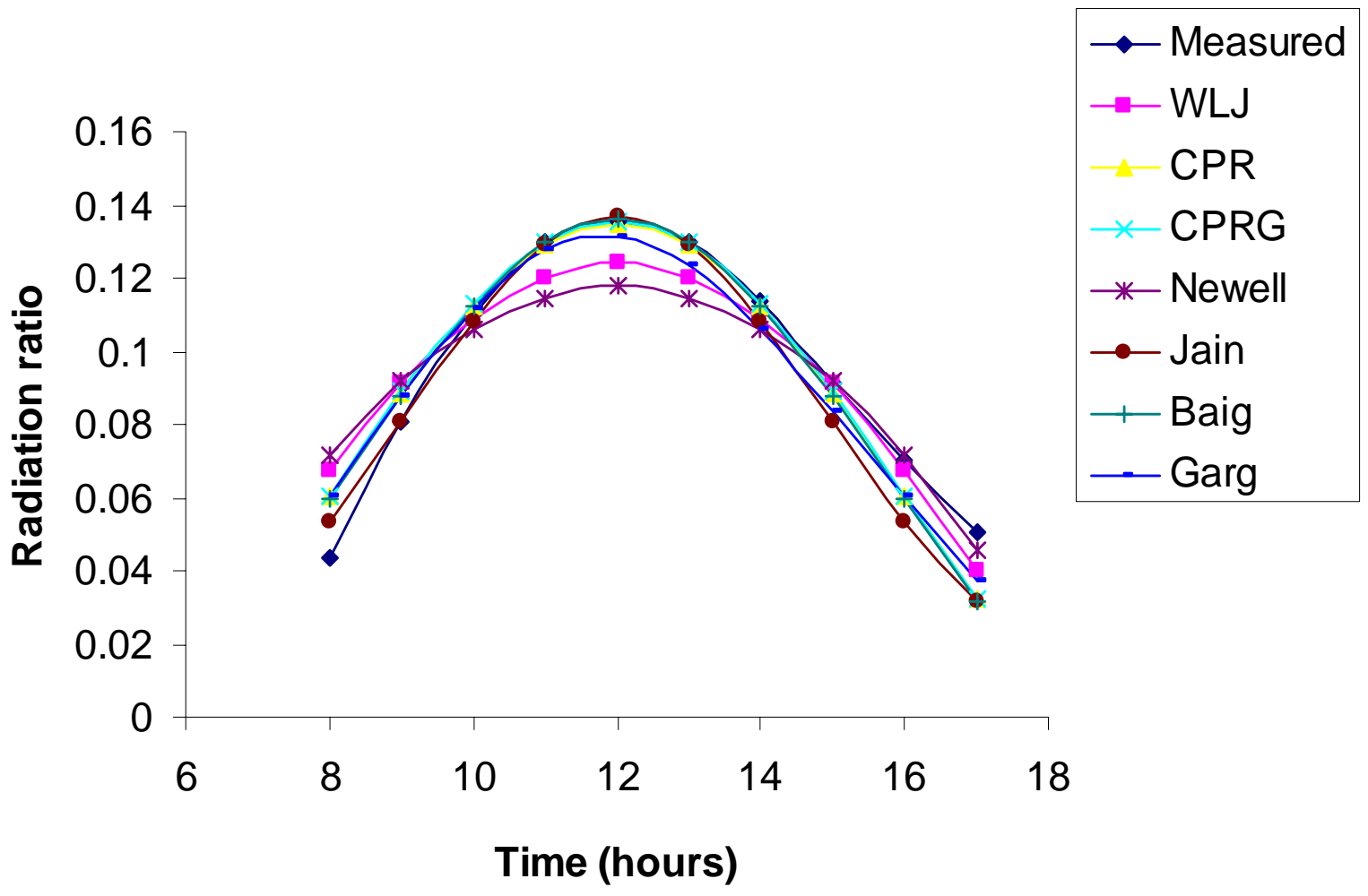

Fig. (1). Measured and estimated ratios of monthly mean hourly to daily global radiation for the month of June at Bangalore.

Table 5. Percentage Root Mean Square Error (RMSE) between Predicted Results and Measured Monthly-Mean Hourly Irradiation for Location Jodhpur

\begin{tabular}{|c|c|c|c|c|c|c|c|c|}
\hline & & WLJ & CPR & CPRG & Newell & Jain & Baig & Garg \\
\hline January & RMSE & 15.8 & 16.3 & 16.4 & 16.6 & 16.9 & 17.7 & 17.1 \\
\hline \multirow{2}{*}{ February } & RMSE & 13.7 & 14.8 & 14.9 & 14.5 & 16 & 16 & 15.2 \\
\hline & MBE & -2 & -2.3 & -1.5 & -2.2 & -5.7 & -3.7 & -3 \\
\hline March & RMSE & 12 & 13.4 & 13.4 & 13 & 15.5 & 14.2 & 13.8 \\
\hline \multirow{2}{*}{ April } & RMSE & 11.97 & 12.6 & 12.5 & 13.5 & 15.4 & 13 & 13.6 \\
\hline & MBE & -5.7 & -5.1 & -4.4 & -6.5 & -8.6 & -5.3 & -6.7 \\
\hline \multirow{2}{*}{ May } & RMSE & 12.4 & 11.9 & 11.7 & 14.7 & 15 & 12 & 13.8 \\
\hline & MBE & -7.6 & -6.5 & -6 & -8.9 & -10 & -6.5 & -8.7 \\
\hline \multirow{2}{*}{ August } & RMSE & 12.4 & 12.3 & 12.1 & 14.4 & 15.2 & 12.5 & 13.8 \\
\hline & MBE & -6.5 & -5.6 & -5.1 & -7.5 & -9.2 & -5.7 & -7.6 \\
\hline \multirow{2}{*}{ September } & RMSE & 12.3 & 12.6 & 12.5 & 13.9 & 15 & 13.2 & 13.6 \\
\hline & MBE & -4.3 & -4.1 & -3.3 & -4.9 & -7.6 & -4.5 & -5.4 \\
\hline \multirow{2}{*}{ October } & RMSE & 13.3 & 14.1 & 14.2 & 14.4 & 15.6 & 15.1 & 14.7 \\
\hline & MBE & -2.4 & -2.7 & -1.8 & -2.7 & -6.1 & -3.8 & -3.5 \\
\hline \multirow{2}{*}{ November } & RMSE & 15.6 & 16.5 & {$[86] 6$} & 16.3 & 17.3 & 17.9 & 17.1 \\
\hline & MBE & -1.3 & -1.8 & -0.9 & -1.4 & -4.9 & -3.8 & -2.3 \\
\hline December & RMSE & 15.9 & 16.7 & 16.9 & 16.6 & 17.2 & 18.4 & 17.5 \\
\hline
\end{tabular}


Table 6. Percentage Root Mean Square Error (RMSE) between Predicted Results and Measured Monthly-Mean Hourly Irradiation for Location Mumbai

\begin{tabular}{|c|c|c|c|c|c|c|c|c|}
\hline & & WLJ & CPR & CPRG & Newell & Jain & Baig & Garg \\
\hline \multirow{2}{*}{ January } & RMSE & 17.5 & 18.2 & 18.2 & 18.2 & 18.9 & 19.2 & 18.9 \\
\hline & MBE & -1.7 & -2.2 & -1.3 & -1.9 & -5.5 & -3.7 & -2.8 \\
\hline \multirow{2}{*}{ February } & RMSE & 16.2 & 16.8 & 16.9 & 17 & 17.9 & 17.7 & 17.5 \\
\hline & MBE & -2.5 & -2.7 & -1.8 & -2.8 & -6.2 & -3.8 & -3.6 \\
\hline \multirow{2}{*}{ March } & RMSE & 16.4 & 16.8 & 16.8 & 17.4 & 18.2 & 17.4 & 17.7 \\
\hline & MBE & -3.7 & -3.6 & -2.8 & -4.2 & -7.1 & -4.2 & -4.7 \\
\hline \multirow{2}{*}{ April } & RMSE & 15.9 & 15.9 & 15.8 & 17.3 & 17.6 & 16.2 & 17 \\
\hline & MBE & -5.1 & -4.7 & -3.9 & -5.9 & -8.2 & -4.9 & -6.2 \\
\hline \multirow{2}{*}{ May } & RMSE & 16 & 15.3 & 15.2 & 17.8 & 17.2 & 15.5 & 16.8 \\
\hline & MBE & -6.4 & -5.6 & -5 & -7.4 & -9.2 & -5.7 & -7.5 \\
\hline \multirow{2}{*}{ June } & RMSE & 14.6 & 14.3 & 14.1 & 16.5 & 16.7 & 14.4 & 15.7 \\
\hline & MBE & -7.1 & -6.1 & -5.6 & -8.2 & -9.6 & -6.1 & -8.2 \\
\hline \multirow{2}{*}{ July } & RMSE & 23 & 24.4 & 24.3 & 23.3 & 27 & 24.7 & 25.3 \\
\hline & MBE & -6.8 & -5.8 & -5.3 & -7.8 & -9.4 & -5.9 & -7.8 \\
\hline \multirow{2}{*}{ August } & RMSE & 16.3 & 16.9 & 16.8 & 17.4 & 19.5 & 17.3 & 18.1 \\
\hline & MBE & -5.7 & -5.1 & -4.4 & -6.5 & -8.6 & -5.3 & -6.7 \\
\hline \multirow{2}{*}{ September } & RMSE & 14.4 & 14.6 & 14.5 & 15.7 & 16.5 & 15.1 & 15.5 \\
\hline & MBE & -4.2 & -4 & -3.2 & -4.8 & -7.5 & -4.5 & -5.3 \\
\hline \multirow{2}{*}{ October } & RMSE & 12 & 11.6 & 11.5 & 13.8 & 13.4 & 12.4 & 12.6 \\
\hline & MBE & -2.8 & -3 & -2.1 & -3.2 & -6.5 & -3.9 & -3.9 \\
\hline \multirow{2}{*}{ November } & RMSE & 15.4 & 14.9 & 14.8 & 16.8 & 16.1 & 15.7 & 15.9 \\
\hline & MBE & -1.9 & -2.3 & -1.4 & -2.2 & -5.6 & -3.7 & -2.9 \\
\hline \multirow{2}{*}{ December } & RMSE & 16 & 15.7 & 15.7 & 17.2 & 16.7 & 16.7 & 16.6 \\
\hline & MBE & -1.5 & -2 & -1.1 & -1.7 & -5.3 & -3.7 & -2.6 \\
\hline
\end{tabular}

The performances of the seven models to predict mean hourly global radiation from mean daily global radiation were evaluated using the root mean square and mean bias error tests. The results of the statistical comparison of the seven models are presented in Tables 3-7.

For moderate climate of Bangalore, the evaluated values of percentage root mean square error (RMSE) and percentage mean bias error (MBE) for radiation ratio have been given in Table 4 for each month. The values of RMSE and MBE both are minimum for the model proposed by Newell (Equation 8) during the months from January to April. During the remaining eight months of the year, the values of RMSE and MBE both are minimum for the model proposed by CPRG (Equation 6). Hence this model gives closer results in comparison to others.

For desertic (hot and dry) climate of Jodhpur, the evaluated values of percentage root mean square error (RMSE) and percentage mean bias error $(\mathrm{MBE})$ for radiation ratio have been given in Table 5 for each month. The values of
RMSEs are minimum during months from January to April and September to December for the model proposed by WLJ (Equation 4). The values of RMSEs are minimum during months from May to August for the model proposed by CPRG (Equation 6). The values of MBEs are minimum during all months of the year for the model proposed by CPRG (Equation 6). Hence this model gives closer results in comparison to others.

For coastal (warm and humid) climate of Mumbai, the evaluated values of percentage root mean square error (RMSE) and percentage mean bias error (MBE) for radiation ratio have been given in Table 6 for each month. WLJ model (Equation 4) yields minimum RMSEs during months from January to March and July to September. CPRG model (Equation 6) yields minimum RMSEs during months from April to June and from October to December. CPRG model (Equation 6) gives minimum MBEs during all months of the year. Hence this model gives closer results in comparison to others. 
For composite climate of New Delhi, the evaluated values of percentage root mean square error (RMSE) and percentage mean bias error (MBE) for radiation ratio have been given.

In Table 7 for each month. WLJ, CPR and CPRG models give minimum (almost equal) RMSEs during months from January to April. CPRG model gives minimum RMSEs during the months from May to August. CPR and CPRG models give minimum (almost equal) RMSEs during the months from September to December. Again CPRG model gives minimum MBEs during all months of the year. Hence this model gives closer results in comparison to others.

For cold and cloudy climate of Srinagar, the evaluated values of percentage root mean square error (RMSE) and percentage mean bias error (MBE) for radiation ratio have been given in Table $\mathbf{8}$ for each month. CPRG model gives the best results in terms of RMSEs and MBEs during all months of the year. Hence this model gives closer results in comparison to others. CPR model is next best with the smallest range of MBEs.

CPRG model generally gives the best results for clear sky conditions of Indian regions. The low MBEs are particularly remark-able. Therefore, its use is recommended for Indian regions.

\section{ACKNOWLEDGEMENTS}

The authors are grateful to the Indian Meteorological Department, Pune, India for providing the hourly global and diffuse radiation data for the period of 11 years from 1991 to 2001.

Table 7. Percentage Root Mean Square Error (RMSE) between Predicted Results and measured Monthly-Mean Hourly Irradiation for Location New Delhi

\begin{tabular}{|c|c|c|c|c|c|c|c|c|}
\hline & & WLJ & CPR & CPRG & Newell & Jain & Baig & Garg \\
\hline \multirow{2}{*}{ January } & RMSE & 13.7 & 13.4 & 13.5 & 15 & 14.6 & 14.9 & 14.4 \\
\hline & MBE & -0.9 & -1.5 & -0.7 & -1.1 & -4.5 & -4 & -2 \\
\hline \multirow{2}{*}{ February } & RMSE & 14.5 & 14.6 & 14.6 & 15.7 & 15.7 & 15.6 & 15.4 \\
\hline & MBE & -1.8 & -2.2 & -1.3 & -2 & -5.6 & -3.7 & -2.9 \\
\hline \multirow{2}{*}{ March } & RMSE & 14.6 & 16.1 & 16.1 & 15.3 & 17.9 & 16.8 & 16.4 \\
\hline & MBE & -3.5 & -3.5 & -2.6 & -4 & -7 & -4 & -4.5 \\
\hline \multirow{2}{*}{ April } & RMSE & 11.5 & 11.5 & 11.4 & 13.4 & 14.4 & 11.9 & 12.8 \\
\hline & MBE & -5.9 & -5.2 & -4.5 & -6.7 & -8.7 & -5.4 & -6.9 \\
\hline \multirow{2}{*}{ May } & RMSE & 12.5 & 11 & 10.7 & 15.2 & 14.1 & 11 & 13.3 \\
\hline & MBE & -8.1 & -6.8 & -6.4 & -9.3 & -10.3 & -6.8 & -9.1 \\
\hline \multirow{2}{*}{ June } & RMSE & 12.3 & 11 & 10.9 & 15.1 & 14.5 & 11 & 13.4 \\
\hline & MBE & -9.2 & -7.6 & -7.3 & -10.7 & -11.1 & -7.6 & -10.2 \\
\hline \multirow{2}{*}{ July } & RMSE & 13.5 & 12.4 & 12.3 & 15.9 & 15.6 & 12.5 & 14.7 \\
\hline & MBE & -8.6 & -7.2 & -6.8 & -10.1 & -10.7 & -7.2 & -9.7 \\
\hline \multirow{2}{*}{ August } & RMSE & 11.9 & 10.2 & 9.9 & 14.7 & 13 & 10.3 & 12.1 \\
\hline & MBE & -6.8 & -5.8 & -5.3 & -7.8 & -9.4 & -5.9 & -7.8 \\
\hline \multirow{2}{*}{ September } & RMSE & 12.3 & 11.7 & 11.6 & 14.2 & 13.9 & 12.2 & 12.8 \\
\hline & MBE & -4.4 & -4.1 & -3.4 & -5 & -7.7 & -4.6 & -5.5 \\
\hline \multirow{2}{*}{ October } & RMSE & 15.5 & 13.7 & 13.6 & 17.4 & 15 & 14.2 & 15.2 \\
\hline & MBE & -2.3 & -2.6 & -1.7 & -2.6 & -6 & -3.8 & -3.3 \\
\hline \multirow{2}{*}{ November } & RMSE & 14.3 & 12.9 & 12.9 & 15.9 & 14.5 & 14 & 14.3 \\
\hline & MBE & -1.1 & -1.6 & -0.83 & -1.3 & -4.7 & -3.9 & -2.2 \\
\hline \multirow{2}{*}{ December } & RMSE & 15.9 & 15.2 & 15.3 & 17.2 & 16.3 & 16.6 & 16.5 \\
\hline & MBE & -0.88 & -1.4 & -0.62 & -0.99 & -4.2 & -4.3 & -1.9 \\
\hline
\end{tabular}


Table 8. Percentage Root Mean Square Error (RMSE) between Predicted Results and Measured Monthly-Mean Hourly Irradiation for Location Srinagar

\begin{tabular}{|c|c|c|c|c|c|c|c|c|}
\hline & & WLJ & CPR & CPRG & Newell & Jain & Baig & Garg \\
\hline \multirow{2}{*}{ January } & RMSE & 15.6 & 15.4 & 15.5 & 16.7 & 17.4 & 17.2 & 16.4 \\
\hline & MBE & -0.87 & -1.3 & -0.6 & -0.99 & -3.8 & -4.6 & -1.9 \\
\hline \multirow{2}{*}{ February } & RMSE & 23.8 & 22.5 & 22.5 & 25 & 23 & 22.9 & 24 \\
\hline & MBE & -1.4 & -1.9 & -1.1 & -1.6 & -5.2 & -3.8 & -2.5 \\
\hline \multirow{2}{*}{ March } & RMSE & 16.6 & 16.1 & 16 & 18.1 & 17.6 & 16.6 & 17.3 \\
\hline & MBE & -3.4 & -3.4 & -2.6 & -3.9 & -6.9 & -4.1 & -4.5 \\
\hline \multirow{2}{*}{ April } & RMSE & 11.5 & 9.7 & 9.4 & 14.4 & 13.1 & 10 & 12.1 \\
\hline & MBE & -6.4 & -5.6 & -4.9 & -7.3 & -9.1 & -5.7 & -7.4 \\
\hline \multirow{2}{*}{ May } & RMSE & 14.1 & 11.1 & 10.8 & 17.6 & 13.9 & 11.1 & 14.2 \\
\hline & MBE & -9.1 & -7.5 & -7.3 & -10.6 & -11 & -7.5 & -10.2 \\
\hline \multirow{2}{*}{ June } & RMSE & 14.4 & 12.4 & 12.3 & 17.5 & 15.6 & 12.4 & 15.4 \\
\hline & $\mathrm{MBE}$ & -10.5 & -8.6 & -8.5 & -12.3 & -12.1 & -8.6 & -11.6 \\
\hline \multirow{2}{*}{ July } & RMSE & 14.4 & 10.6 & 10.4 & 18.3 & 13.4 & 10.6 & 14 \\
\hline & MBE & -9.9 & -8.1 & -7.9 & -11.5 & -11.6 & -8.1 & -10.9 \\
\hline \multirow{2}{*}{ August } & RMSE & 16.1 & 13.9 & 13.7 & 18.8 & 16.2 & 14 & 16.4 \\
\hline & MBE & -7.5 & -6.4 & -5.9 & -8.7 & -9.9 & -6.4 & -8.6 \\
\hline \multirow{2}{*}{ September } & RMSE & 11.7 & 8.6 & 8.3 & 14.7 & 11.5 & 8.9 & 11 \\
\hline & MBE & -4.5 & -4.2 & -3.4 & -5.1 & -7.7 & -4.6 & -5.5 \\
\hline \multirow{2}{*}{ October } & RMSE & 12 & 8.8 & 8.6 & 14.6 & 11.5 & 9.4 & 10.8 \\
\hline & $\mathrm{MBE}$ & -1.9 & -2.3 & -1.4 & -2.2 & -5.7 & -3.7 & -3 \\
\hline \multirow{2}{*}{ November } & RMSE & 17.6 & 14.1 & 14 & 19.6 & 16.5 & 14.4 & 16.2 \\
\hline & MBE & -0.9 & -1.4 & -0.6 & -1 & -4.2 & -4.3 & -1.9 \\
\hline \multirow{2}{*}{ December } & RMSE & 20 & 18.9 & 19 & 21.1 & 19.3 & 20.4 & 20.6 \\
\hline & MBE & -1 & -1.3 & -0.7 & -1.2 & -3.5 & -5.1 & -2.1 \\
\hline
\end{tabular}

\section{REFERENCES}

[1] Whillier A. Solar energy collection and its utilization for house heating, M.I.T., Cambridge, 1953.

[2] Whillier A. The determination of hourly values of total solar radiation from daily summations. Arch. Met. Geophys. Biokl 1956; B8: 197-204.

[3] Hottel HC, Whillier A. Evaluation of flat plate solar collector performance. Proc Trans Conf Use of Solar Energy: The Scientific Basis 1955; 2(1): 74-104.

[4] Liu B. YH, Jordan RC. The interrelationship and characteristic distribution of direct, diffuse and total solar radiation. Solar Energy 1960; 4: 1-12.

[5] Benseman RF, Cook FW. Solar radiation in New Zealand-The standard year and radiation on inclined slopes. New Zealand J Sci 1969; 12: 696-708.

[6] Iqbal M. A study of Canadian diffuse and total solar radiation data-II Monthly average hourly horizontal radiation. Solar Energy 1979; 22: 87-90.

[7] Collares-Pereira M, Rabl A. The average distribution of solar radiation: Correlations between diffuse and hemispherical and between daily and hourly insolation values. Solar Energy 1979; 22: 155164.

[8] Gueymard C. Monthly averages of the daily effective optical air mass and solar related angles for horizontal or inclined surfaces. J Solar Energy Eng Trans ASME, 1986.
[9] Jain PC. Comparison of techniques for the estimation of daily global irradiation and a new technique for the estimation of hourly global irradiation. Solar Wind Technol 1984; 1: 123-134.

[10] Vignola F, McDaniels DK. Direct beam radiation: Projection onto tilted surfaces. Solar Energy 1988; 40: 237-247.

[11] Zelenka A. Asymmetrical analytically weighted Rb factors. Solar Energy 1988; 41: 405-415.

[12] Bivona S, Burlon R, Leone C. Instantaneous distribution of global and diffuse radiation on a horizontal surface. Solar Energy 1991; 46: $249-254$

[13] Satyamurty VV, Lahiri PK. Estimation of symmetric and asymmetric hourly global and diffuse radiation from daily values. Solar Energy 1992; 48: 7-14.

[14] Soler A, Gopinathan KK. Estimation of monthly mean hourly global radiation for latitudes in the $18 \mathrm{~N}-818 \mathrm{~N}$ range. Solar Energy 1994; 52: 233-239.

[15] Russo G. Analytical model and simulation code for the solar input determination: irradiance maps. Solar Energy 1978; 21: 201-210.

[16] Schwartz LM, Louat R, Menguy G. Etude du rayonnement solaire global a Lyon et Macon. Rev Phys Appl 1980; 15: 103-112.

[17] Newell TA. Simple models for hourly to daily radiation ratio correlations. Solar Energy 1983; 31:339-342.

[18] Munroe MM. Estimation of totals of irradiance on a horizontal surface from UK average meteorological data. Solar Energy 1980; 24: $235-238$ 
[19] Graham VA, Hollands KGT, Unny TE. Stochastic variation of hourly radiation over the day. In Advances in Solar Energy Technology. Proc ISES Congress, Pergamon Press 1987; 4: 3796-3800.

[20] Baig A, Akhter P, Mufti A. A novel approach to estimate the clear day global radiation. Renew Energy 1991; 1: 119-123.

[21] Aguiar R, Collares-Pereira M. TAG: A Time dependent, autoregressive Gaussian model for generating synthetic hourly radiation. Solar Energy 1992; 49: 167-174.

[22] Jain PC, Jain S, Ratto CF. A new model for obtaining horizontal instantaneous global and diffuse radiation from the daily values. Solar Energy 1988; 41: 397-404.
[23] Duffie JA, Beckman WA. Solar Engineering of Thermal Processes, $3^{\text {rd }}$ ed; Wiley: New York, 1990.

[24] Iqbal M. An Introduction to Solar Radiation, Academic Press: Toronto, 1983.

[25] Garg HP, Garg SN. Improved correlation of daily and hourly diffuse radiation with global radiation for Indian stations. Solar Wind Technol 1987; 4: 113-126.

[26] Cumumo M, Rosa ADe, Ferraro V, Kaliakatsos D, Marinelli V. Experimental testing of models for the estimation of hourly solar radiation on vertical surfaces at Arcavacata di Rende. Solar Energy 2007; 81: 692-695.

Received: January 22, 2008

Revised: January 31, 2008

Accepted: February 1, 2008

(C) Ahmad and Tiwari; Licensee Bentham Open.

This is an open access article distributed under the terms of the Creative Commons Attribution License (http://creativecommons.org/licenses/by/2.5/), which permits unrestrictive use, distribution, and reproduction in any medium, provided the original work is properly cited. 